\title{
An improved method for gastric tube and anastomotic anvil placement during thoracoscopic and laparoscopic Ivor Lewis esophagectomy
}

\author{
Yi Shen ${ }^{1}$, Yunfeng Zhou ${ }^{1}$ and Xiang Zhuang ${ }^{2^{*}}$
}

\begin{abstract}
Background: During esophagectomy for esophageal cancer, a gastric tube is necessary for the perioperative period. However, the gastric tube and anastomotic anvil placement is often extremely difficult and time consuming during surgery.

Methods: We used the traditional method or improved method to place the gastric tube and anastomotic anvil during thoracoscopic and laparoscopic Ivor Lewis esophagectomy. Thirty-seven patients were in the improved group: the gastric tube and anastomotic anvil were placed using the improved method; 35 patients were in the traditional group: the gastric tube and anastomotic anvil were placed using the traditional method. Retrospectively, we analyze the basic clinical characteristics, perioperative clinical features, and postoperative complications of the two groups of patients.

Results: The two groups were matched well for baseline characteristics. There was no significant difference between the two groups in blood loss, postoperative hospital stay, postoperative fasting time, drainage volume, and overall complications. But significant between-group differences were observed in time consuming and chest tube indwelling time $(P<0.05)$, both of which were significantly shorter in the improved group than in the traditional group.
\end{abstract}

Conclusions: This improved method can reduce the difficulty of placing anastomotic anvil and gastric tube and prevent damage to the anastomosis during surgery.

\section{Introduction}

During esophagectomy for esophageal cancer, a gastric tube can be placed for gastrointestinal decompression, alleviation of postoperative abdominal distention, reduction of anastomotic pressure, and observation of anastomotic bleeding. In thoracoscopic and laparoscopic Ivor Lewis esophagectomy, a gastric tube is typically placed

\footnotetext{
* Correspondence: 2940075760@qq.com

${ }^{2}$ Department of Thoracic Surgery, Sichuan Cancer Hospital, School of Medicine, University of Electronic Science and Technology of China, Chengdu 610041, China

Full list of author information is available at the end of the article
}

in the patient through the nasal cavity after anastomosis. However, due to uncertainty regarding the direction of the gastric tube tip, tube placement is often extremely difficult, requires a lengthy duration, and can even cause damage to the anastomosis. Additionally, when the anastomotic anvil is placed prior to anastomosis, there is no directional traction during delivery of the anastomotic anvil and the operation is often time consuming. Moreover, violent delivery of the anvil may also lead to anastomotic damage. Using the technique described here, we have improved the method of anastomotic anvil and

(c) The Author(s). 2020 Open Access This article is licensed under a Creative Commons Attribution 4.0 International License, which permits use, sharing, adaptation, distribution and reproduction in any medium or format, as long as you give appropriate credit to the original author(s) and the source, provide a link to the Creative Commons licence, and indicate if changes were made. The images or other third party material in this article are included in the article's Creative Commons licence, unless indicated otherwise in a credit line to the material. If material is not included in the article's Creative Commons licence and your intended use is not permitted by statutory regulation or exceeds the permitted use, you will need to obtain permission directly from the copyright holder. To view a copy of this licence, visit http://creativecommons.org/licenses/by/4.0/. The Creative Commons Public Domain Dedication waiver (http://creativecommons.org/publicdomain/zero/1.0/) applies to the data made available in this article, unless otherwise stated in a credit line to the data. 
gastric tube placement to reduce not only the placement duration but also the incidence of anastomotic damage.

\section{Technique}

\section{Laparoscopic phase}

The patient was placed in a supine position. A total of five abdominal ports were used, including two 5-mm ports, two $10-\mathrm{mm}$ ports, and one $12-\mathrm{mm}$ port. An artificial pneumoperitoneum was established using $\mathrm{CO}_{2}$. Perigastric tissue was transected, and the abdominal lymph nodes were cleaned. A tubular stomach was formed using a straight cutting stapler under laparoscopy.

\section{Thoracoscopic phase}

The patient was placed in the left lateral decubitus position. A total of four ports were established, including a 10-mm observation port (at the seventh intercostal space along the midaxillary line), a $40-\mathrm{mm}$ main operation port (at the fourth intercostal space along the anterior axillary line), a 5-mm auxiliary port (at the seventh intercostal space along the infrascapular line), and a $10-\mathrm{mm}$ suboperation port (at the ninth intercostal space along the posterior axillary line). The thoracic esophagus was dissociated, and the mediastinal lymph nodes were cleaned. The esophagus was transected $6 \mathrm{~cm}$ from the top edge of the tumor. The tumor and part of the gastric tissue were extracted.

\section{Placement of the gastric tube and anastomotic anvil}

(1) A no. 7 thread that would be used to pull the anastomotic anvil was ligated to the top of the mushroom head of the anastomotic anvil (Fig. 1). (2) The gastric tube was placed into the esophagus through the nasal cavity, the stomach tube was drag out of the chest cavity through the esophagus stump, and the anastomotic anvil and gastric tube were connected using the threads (Fig. 2). (3) The

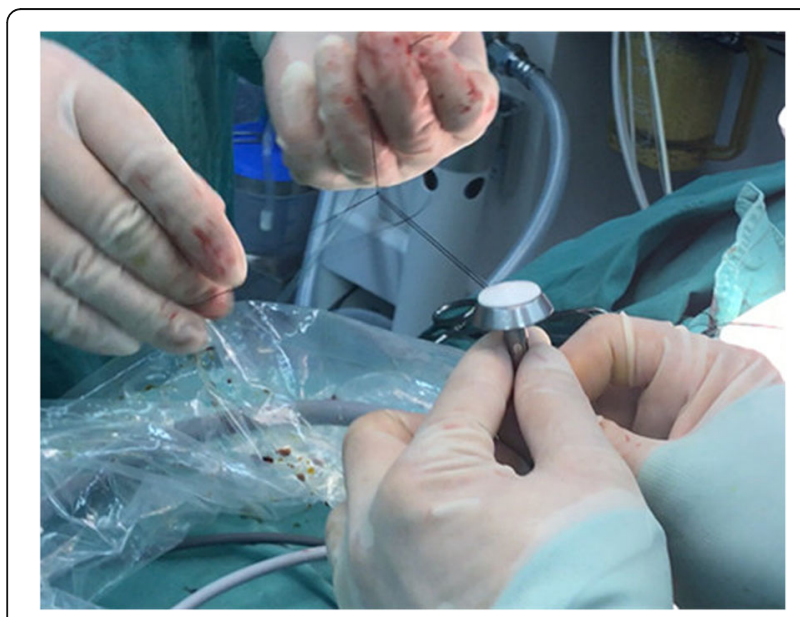

Fig. 1 A thread was ligated to the top of the mushroom head of the anastomotic anvil

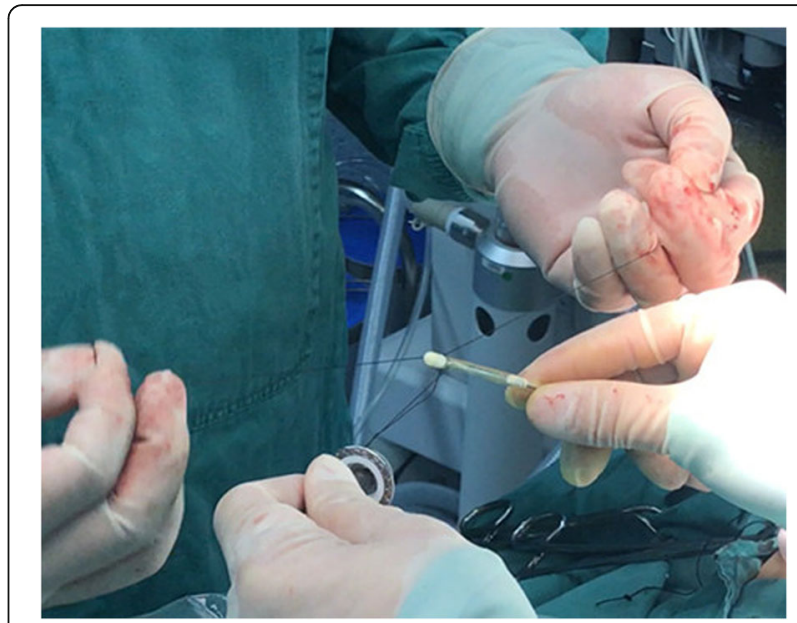

Fig. 2 Anastomotic anvil and gastric tube were connected using the threads

anastomotic anvil was pulled to the anastomotic area of the esophageal stump by pulling the gastric tube (Fig. 3). (4) Esophagogastric side-to-side anastomosis was performed using reverse-puncture anastomotic technique [1]. (5) Pull the tip of the gastric tube near the anastomosis by pulling the anastomotic anvil. The traction thread at the tip of the gastric tube was cut, and the anastomotic anvil was removed. (6) Put the tip of the gastric tube into the tubular stomach through the anastomosis, and push the gastric tube to an appropriate position in the stomach. The anastomosis was completed by closing the gastric stump using a stapler. The operation ports were closed after placement of a thoracic drainage tube and a mediastinal drainage tube at the observation port and the port at the ninth intercostal space, respectively.

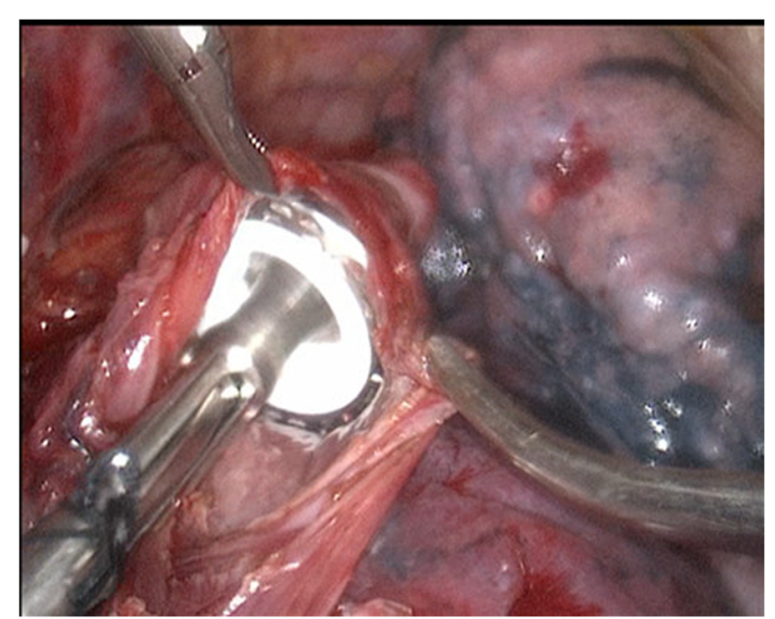

Fig. 3 The anastomotic anvil was pulled to the anastomotic area 


\section{Results}

The clinical data of 72 patients undergoing Ivor Lewis esophagectomy were retrospectively analyzed. Thirtyseven patients were in the improved group, the gastric tube and anastomotic anvil were placed using the above method, while the traditional group was using the traditional method.

The two groups were matched well for baseline characteristics including sex, age, history of smoking and drinking, tumor location, pathologic stage, histological type, and comorbidities (Table 1).

There was no significant difference between the two groups in blood loss, postoperative hospital stay, postoperative fasting time, and drainage volume. But significant between-group differences were observed in time consuming and chest tube indwelling time $(P<0.05)$, both of which were significantly shorter in the improved group than in the traditional group (Table 2).

There was no significant difference between the two groups in the overall complication rate, the incidence of anastomotic leakage, pulmonary infection, arrhythmia, wound infection, or recurrent laryngeal nerve palsy (Table 3).

\section{Discussion}

Shortly after esophagectomy, patients often exhibit delayed gastric emptying, gas and secretions in the gastrointestinal tract, and occasional bleeding at the anastomosis or the gastric margin, leading to the accumulation of gastrointestinal contents, which causes gastric dilatation [2]. Gastric dilatation increases tension at the anastomosis, increasing the incidence of anastomotic leakage. Moreover, increased stomach tension may also lead to vomiting, which increases

Table 1 Basic clinical characteristics

\begin{tabular}{llll}
\hline Characteristics & $\begin{array}{l}\text { Improved group } \\
(n=37)\end{array}$ & $\begin{array}{l}\text { Traditional group } \\
(n=35)\end{array}$ & $P$ value \\
\hline Age (years) & $56.5 \pm 10.2$ & $53.9 \pm 9.7$ & 0.279 \\
Gender (male/female) & $25 / 12$ & $24 / 11$ & 0.927 \\
Smoking & 27 & 21 & 0.243 \\
Drinking & 18 & 16 & 0.803 \\
Tumor location & $6 / 31$ & $9 / 26$ & 0.321 \\
(middle/lower) & & & \\
Pathologic stage & & 8 & 0.445 \\
I & 11 & 23 & \\
II & 19 & 4 & 0.472 \\
$\quad$ III & 7 & & \\
Histological type & & 33 & 0.422 \\
$\quad$ Squamous cell & 32 & 2 & \\
Adenocarcinoma & 5 & 6 & \\
Comorbidities & 3 & & \\
\hline
\end{tabular}

"Hypertension, diabetes, etc.
Table 2 Perioperative clinical features between the two groups

\begin{tabular}{|c|c|c|c|}
\hline Clinical features & $\begin{array}{l}\text { Improved group } \\
(n=37)\end{array}$ & $\begin{array}{l}\text { Traditional group } \\
(n=35)\end{array}$ & $P$ value \\
\hline Time consuming ${ }^{\#}(\mathrm{~min})$ & $21.3 \pm 2.7$ & $24.8 \pm 3.1$ & 0.000 \\
\hline Blood loss (ml) & $337.6 \pm 137.0$ & $302.7 \pm 138.2$ & 0.286 \\
\hline $\begin{array}{l}\text { Postoperative hospital } \\
\text { stay (days) }\end{array}$ & $11.1 \pm 2.6$ & $11.7 \pm 3.1$ & 0.254 \\
\hline Chest tube stay (days) & $4.4 \pm 1.8$ & $5.5 \pm 3.4$ & 0.023 \\
\hline $\begin{array}{l}\text { Postoperative fasting } \\
\text { time (days) }\end{array}$ & $6.6 \pm 2.0$ & $7.1 \pm 3.2$ & 0.326 \\
\hline Drainage volume (ml) & $1122.3 \pm 228.1$ & $1047.6 \pm 221.4$ & 0.163 \\
\hline
\end{tabular}

"Gastric tube placement and esophagogastric anastomosis time consuming

the risk of aspiration pneumonia [3]. Therefore, it is extremely important to place a gastric tube after esophagectomy and induce early gastrointestinal decompression [4] such that gas and secretions can be removed in a timely manner, thereby reducing tension in the stomach and at the anastomosis, ameliorating the corrosive effect of gastric acid on the anastomosis, and enabling the detection of bleeding of the surgical wound.

This study shows that the incidence of anastomotic leakage in the traditional group is significantly higher than that in the improved group, but the difference is not statistically significant, which may be related to the small sample size.

In terms of placement time, the improved group was significantly shortened. The modified group did not increase surgical trauma and operation time; therefore, the improved method had no effect on postoperative lung infection and recurrent laryngeal nerve injury; just as this study, there is no statistically significant difference in complications.

Traditionally, the gastric tube has been placed blindly after completion of the anastomosis. Since it is often difficult for the tip of the gastric tube to pass through the relatively narrow anastomotic region, tube placement can cause anastomotic damage and may lead to postoperative anastomotic leakage. During prior Ivor Lewis procedures, when placing the mushroom head of the anastomotic anvil, the surgeon would position the head into the esophageal anastomotic area by clamping the

Table 3 Postoperative complication between the two groups

\begin{tabular}{llll}
\hline Complications & $\begin{array}{l}\text { Improved group } \\
(n=37)\end{array}$ & $\begin{array}{l}\text { Traditional } \\
(n=35)\end{array}$ & group \\
\hline Total complications & $7(18.9 \%)$ & $9(25.7 \%)$ & 0.488 \\
Leakage from anastomosis & $1(2.7 \%)$ & $4(11.4 \%)$ & 0.321 \\
Pneumonia & $4(10.8 \%)$ & $3(8.6 \%)$ & 1.000 \\
Arrhythmia & $1(2.7 \%)$ & $2(5.7 \%)$ & 0.961 \\
$\begin{array}{l}\text { Chylous fistula } \\
\text { Recurrent laryngeal }\end{array}$ & 0 & $1(2.9 \%)$ & 1.000 \\
nerve paralysis & $2(5.4 \%)$ & $1(2.9 \%)$ & 1.000 \\
\hline
\end{tabular}


center rod with forceps. A thoracoscopic operation requires skilled surgical techniques, and improper operations are often lengthy and can even cause mucosal damage in the anastomotic area.

Therefore, the improved method that we used for placing the gastric tube and anastomotic anvil has the following advantages. (1) The anastomotic anvil can be smoothly and rapidly placed into the anastomotic area by pulling the gastric tube, and improper operationinduced damage to the anastomosis can be prevented. (2) After completion of the anastomosis, the gastric tube can be smoothly pulled underneath the anastomotic stoma by pulling the anastomotic anvil, shortening the gastric tube placement time and preventing injury to the anastomotic stoma caused by the tip of the gastric tube. However, this method has many steps, and at the same time, the gastric tube is pulled out of the esophagus stump to increase the risk of infection. This method needs to be further improved.

In summary, placing the gastric tube and anastomotic anvil using the pulling method not only is simple, easy to learn, and safe but also allows for rapid operations; thus, this approach merits widespread application in clinical practice.

\section{Acknowledgements}

Not applicable.

\section{Authors' contributions}

YS and XZ designed the surgical procedure. YS and YFZ collected the patients' clinical information and wrote the paper. The authors read and approved the final manuscript.

\section{Funding}

The authors declare no financial support.

\section{Availability of data and materials}

As a technical innovation, all data generated or analyzed are included in this published article.

\section{Ethics approval and consent to participate}

Not applicable.

\section{Consent for publication}

Written informed consent for publication was obtained from all participants.

\section{Competing interests}

The authors declare that they have no competing interests.

\section{Author details}

${ }^{1}$ Department of Thoracic Surgery, West China School of Public Health and West China Fourth Hospital, Sichuan University, Chengdu 610041, China.

${ }^{2}$ Department of Thoracic Surgery, Sichuan Cancer Hospital, School of Medicine, University of Electronic Science and Technology of China, Chengdu 610041, China.

Received: 1 January 2020 Accepted: 20 May 2020

Published online: 28 May 2020

\section{References}

1. Xiao P, Zhuang X, Shen Y, et al. Reverse-puncture anastomotic technique for minimally invasive Ivor-Lewis esophagectomy. Ann Thorac Surg. 2015; 100(6):2372-5.
2. Poghosyan T, Gaujoux S, Chirica M, et al. Functional disorders and quality of life after esophagectomy and gastric tube reconstruction for cancer. J Visc Surg. 2011;148(5):327-35.

3. Weijs TJ, Kumagai K, Berkelmans GH, et al. Nasogastric decompression following esophagectomy: a systematic literature review and meta-analysis. Dis Esophagus. 2017:30:1-8.

4. Eberhard KE, Achiam MP, Rolff HC, et al. Comparison of "nil by mouth" versus early oral intake in three different diet regimens following esophagectomy. World J Surg. 2017;41:1575-83.

\section{Publisher's Note}

Springer Nature remains neutral with regard to jurisdictional claims in published maps and institutional affiliations.

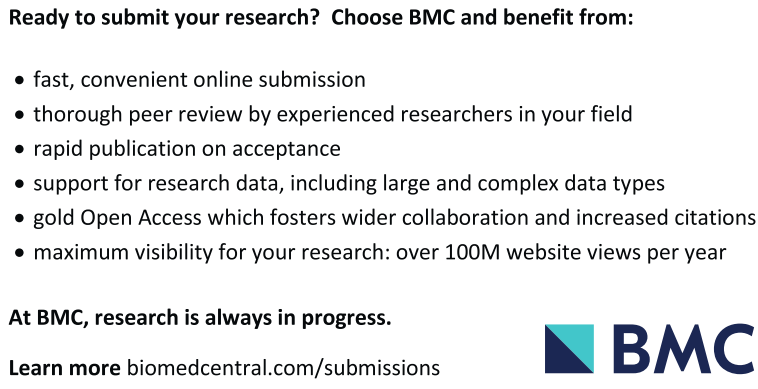

- fast, convenient online submission

- thorough peer review by experienced researchers in your field

- rapid publication on acceptance

- support for research data, including large and complex data types

- gold Open Access which fosters wider collaboration and increased citations

- maximum visibility for your research: over $100 \mathrm{M}$ website views per year

At BMC, research is always in progress.

Learn more biomedcentral.com/submissions 